\title{
Geophysical Characterization of an Alluvial Plain: Case of Karfiguela in Burkina Faso
}

\author{
Nestor Fiacre Compaore and Samuel Nakolendousse*
}

Department of Earth Sciences, Georesources Laboratory, Ouagal University, Burkina Faso

*Corresponding author

\section{A B S T R A C T}

\begin{tabular}{|l|}
\hline Ke y w o r d s \\
Characterization, \\
Alluvial plain, \\
Electrical \\
tomography, \\
Hydraulic \\
conductivity, \\
Karfiguela \\
floodplain \\
(Banfora), Burkina \\
faso (West Africa)
\end{tabular}

\section{Introduction}

The management of water resources is one of the fundamental issues of the world water problem. Indeed, the increasing complexity of the mobilization systems, the use of water resources linked to the increase of the levies and the rejections due to the demographic growth, the economic development, threaten more and more the quantity and the quality of this vital resource (Dezetter, 1998) (1). In Burkina Faso, the assessment of renewable water resources is estimated at $852 \mathrm{~m} 3$ / year / inhabitant while the scarcity threshold is estimated at $1000 \mathrm{~m} 3$ / year / inhabitant (DGH, 2001) (2). Burkina is therefore in a deficit situation with regards to management of water resources. Of all water-consuming activities, agriculture accounts for $64 \%$ of Burkina Faso's total water demand, and much of this demand is met from surface water, which is threatened by the fast drying up in the dry season (DGH, 2001) (2).

Our study is part of the activities carried out 
by the PADI Project BF101 "Sustainable Management of Groundwater for Irrigated Agriculture".

This is indeed a quantitative assessment of the groundwater resources of the alluvial plain of Karfiguelathanks to the assessment of the aquifer through the characterization of materials and the estimate of its flowpower.

\section{Study area}

The study area is the alluvial plain of Karfiguela. It is located in the extreme southwest of Burkina Faso in the province of Comoe whose administrative center is Banfora and in the Cascades region (Figure 1). This plain is located approximately between $4^{\circ}$ $36 ' 34$ "and $4{ }^{\circ}$ 49'19" west longitude and between $10^{\circ} 28^{\prime} 36$ "and $10^{\circ}$ 43'20" north latitude (NESTOR, 2017) (3). The plain has an area of about 4580 .

The Karfiguela plain is characterized by five (5) geological formations (Figure 2): KawaraSindou Formation, Lower Sandstone Formation, Shale and Volcano-Sediment Formation, Granodiorite Formation, and Tonalitic group.

The sandstones of Kawara-Sindou (60 to $350 \mathrm{~m}$ thick) rest on the lower sandstone or directly on the basement. It is a formation consisting of very fine quartzite sandstone at the base and coarse sandstone above (Figure 6). It is characterized by an oblique stratigraphy and the presence of abundant wave wrinkles (Hugot, 2002) (4) (Fig. 3).

The lower sandstones (50 to $300 \mathrm{~m}$ thick) lie with discrepencies on the base. The formation consists successively from the base to the summit of fine red sandstone, fine quartzite sandstone and red sandstone with schist flow (Hugot, 2002)(4).

Shales and volcano-sediments These rocks present a certain complexity. Indeed, at the weathering, they can be difficult to differentiate with schistosed and weathered andesitic rocks. Globally, they are pelites, sandstone shales, gray-black gloss schists, tuffaceousschists and rare quartzitic horizons (Ouédraogo, 2006) (5).

The granodiorites are granular rocks, mesocratic relatively rich in mafic minerals and feldspars (Hugot, 2002). (5) They constitute the major part of the pedestal at the level of our study site.

The group of Tonalites includes a number of facies ranging from granodiorite to tonalite and quartz diorite. These rocks are globally very close. They are of medium to coarse grain, presenting a planar mill or a clear gneissic foliation. Locally, a ribbon is associated with foliation and gives the rock an aspect of migmatite. They are usually intersected by veins of aplite or pegmatite. In these rocks plagioclase predominates; Potassium feldspar, quartz, amphibole and biotite are less abundant (Ouédraogo, 2006) (5).

The order of magnitude of the total groundwater resources in the Comoé watershed where our study area is located is summarized in Table 1 (Diagnosis of Water Resources in the Commune Watershed, P12, RESO, 1998). The distribution of aquifer reserves is very uneven. In fact, the sedimentary zone that covers $20 \%$ of the basin contains more than half of the aquifer reserves. Renewable infiltration water is estimated at 2530 million $\mathrm{m} 3$, or $13.3 \%$ of annual precipitation (GOMBERT, 1998) (6).

\section{Materials and Methods}

The collection of the study data required the use of the material indicated below: 


\section{Realization of micro-piezometers}

An auger $100 \mathrm{~mm}$ in diameter for drilling;

PVC pipes with a thickness of $2 \mathrm{~mm}$ and a diameter of $90 \mathrm{~mm}$ for the casing.

\section{Piezometric surveys}

A Leica CS10 Differential GPS for the determination of $\mathrm{TN}$ coordinates and altitudes;

A piezometric sensor and various probes, respectively for the manual and automatic measurement of the piezometric level of the structures.

\section{Geophysical campaign}

An acquisition system: the ABEM which contains measurement protocols;

An ABEM resistivity meter that measures the apparent resistivity of the medium;

Two (2) $12 \mathrm{~V}$ batteries;

64 copper electrodes;

4 cables (yellow) to connect the electrodes to the acquisition system, with their coils (take care to tidy the cables so that they are easy to run on the ground and take care not to let the tips drag);

Two cable connectors;

A black cable to connect the resistivity meter to the data logger.

\section{Granulometric analysis by sieving}

An AFNOR standardized sieve column comprising sieves of a dimension between 0.08 and 100 millimeters;

Taresto remove the material;

A precision scale

In addition to the field equipment, we used several technical software. Those are:

SAS4000 Utilities which allowed us to create measurement protocols,
Res2Dinv, to invert the geophysical data, Diver office, for the programming of Divers probes,

Sedlog, which allowed to build lithological sections,

Arc Gis and Surfer for mapping

\section{Méthods used}

There are several methods that can be used on the characterization of alluvial plains (gravimetry, the $\mathrm{H} / \mathrm{V}$ method, tomography). In the case of our study the characterization was done by the tomography technique of the electrical resistivities (ERT) (Maescot, 2008)(8) supported by a series of granulometric analysis and tactile diagnosis on several samples coming from the drilling of the micropiezometers of the plain. The ERT measurement sites were chosen according to the distribution density of the structures (micropiezometers) as shown in the map of Figure 4.

The aim of this survey is to inject into the ground an electric current of intensity I between two electrodes $\mathrm{A}$ and $\mathrm{B}$ and to measure the potential difference $\mathrm{V}$ induced between another pair of electrodes $\mathrm{M}$ and $\mathrm{N}$ (Figure 5).

The apparent electrical resistivity of the subsoil on the basis of Ohm's law is:

$\rho_{\mathrm{a}}=\mathrm{K} \frac{\Delta \mathrm{V}}{\mathrm{I}}$

Where $\mathrm{K}$ is a factor dependent on the geometry of the measuring device

There are several electrode devices used in practice, but the one we chose is the most frequently used measuring device in electrical tomography (GOMBERT, 2008) (8), referred to as the Wenner device (Figure 5). 
With this device, apparent resistivities are less affected by superficial lateral variations and give a good vertical resolution for detecting horizontal layers.

In addition it is well suited to sites where noise is important enough like most of our sites (Figure 6).

The width between electrodes is constant (distance a) and the current electrodes surround the potential electrodes (measurement) as shown in Figure 7.

The preceding equation then becomes:

papp $=2 \pi a \frac{\Delta V}{I}$

It is necessary, to give a good image of the basement, a sufficient density of points. The electrodes, allowing the injection of the current and the measurement of the potential, are placed along a profile (Figure 7).

Figure 7 shows how data is acquired through a Wenner device with 28 electrodes. The principle is the same, regardless of the number of electrodes.

\section{Results and Discussion}

\section{Geological nature of the plain materials}

Geophysical data collected in the field has been inverted to generate geo-electric models. The results of the inversion show that the resistivities on our study site are quite varied (Haladou (2013)) (8), SYMBORO (2016) (9).This verifies the vertical variation of the formations in place.

Indeed, for each range of resistivities corresponds a type of geological formation.

\section{North-west side of the plain}

\section{Site $\mathbf{N}^{\circ} 1$ (Karfiguéla)}

The following observations on the inverted model can be noted: an upper layer of low resistivity ( $<90 \mathrm{ohm} . \mathrm{m})$ is observed from the topographic surface to a depth of about $20 \mathrm{~m}$. This geological formation is attributed to heavily clayey alluviums soaked in water. When going deeper, there is a fairly thin layer of about $4 \mathrm{~m}$ thick with a resistivity $<150$ ohm.m attributed to a sandy arena. This layer rests on two other cumulative thickness formations of about $6 \mathrm{~m}$, and resistivity of between 200 and 400 ohm.m. These layers could be gravel or gravelly sand. A relatively resistant zone (800 to 1000 ohm.m) is observed following the layers mentioned above

The resistivity values of this zone reflect an altered rock, probably the cracked horizon; the base in this zone being granodiorite, there is then at this point cracked granodiorite and the whole resting on a healthy granodiorite resistivity greater than $1000 \mathrm{ohm} . \mathrm{m}$.

From the variations of the resistivities obtained by inversion of geophysical data and relying on the lithological cuttings of our surrounding boreholes, we have established a lithological cutting profile of all the power of the plain in the indicated zone (Figure 10). This scutting shows three types of formations:

A first layer formed of heavily clayed alluvium, more precisely we have a succession of pure clay, sandy clay, silty clay, gritty clay on 20 meters thick.

A second layer of sand and a third layer of gravel. All based on a fractured granodioritic base that becomes healthy deeper.The following figure 10 represents the results of the micro-drilling near the profile on site $\mathrm{N}^{\circ} 1$. These results confirm our conclusions drawn from geophysics in the first meters (Figure 11). Indeed, the stratigraphic logs of PZRG21 and PZRG22 micro-holes located in the vicinity of profile LR00093 show a succession 
of alluvial layers starting from pure clays to very clayey alluviums as it has been observed by geophysics. These alluviums are generally sands, gravel and silts.

\section{West side of the plain}

\section{Site $\mathrm{N}^{\circ} 4$ et $\mathrm{N}^{\circ} 5$ (Diarabakoko)}

The LR106 model of Figure 11 shows a fairly clear tabulation of the different strata encountered in the area. Indeed on the first 20 meters we have a low resistivity layer (<80ohm.m).

This layer consists of clays. From 20 to $27 \mathrm{~m}$ we obtain resistivities characteristic of a sandy arena and below which is a layer of gravel (500 to 700 ohm.m) of $11 \mathrm{~m}$ thick.Par la suite nous observons des résistivités caractéristiques de rochetrèsdure: soclefissuré (1000 à 1500 ohm.m) et soclesain (> 1500ohm.m).

When analyzing the LR107 model, three distinct zones appear: a top layer of medium resistivity, a low resistivity intermediate layer and a lower layer of high resistivity.

The first layer is a mixture of clay sand with pockets of sand or clay in some places. It is surmounted by a thin layer of lateritic cuirass to the southwest. From a depth of $10 \mathrm{~m}$, a clay formation up to about $22 \mathrm{~m}$ deep is observed.

The depth of investigation of the profile does not allow to see clearly the basement but we still see that after the clay layer we have a possible deposition of gravelly sand on the cracked base.

A lithological cutting taking into account all the power of the plain in this zone was made from the resistivity map. This is to obtain the nature and structure of the different materials from the topographic surface to the bedrock.

These sections (Figure 12) show a typical stratification of the plains: at first a deposit of the densest materials such as gravel, followed by a deposit of less dense materials such as sand, to finish with deposits of sand and clay much less dense.

When analyzing the micropiezometer sections made in the vicinity of the profiles used to draw these logs, we see that the results are almost identical except that the drilling cuts are much more precise because these sections show the heterogeneities that often go unnoticed with geophysics (Figure 13).

\section{Assessment and characterization of the power}

Furthermore, in addition to help us determining the nature of materials, geophysical models allow us to determine the power of the plain. Indeed these models are built in a reference $(\mathrm{X}, \mathrm{Z})$. This allows to see the depth investigated by the profile. Also, from these models we have built lithological sections that show the thickness of each of the layers encountered up to the bedrock. Thus we can directly estimate the total power of the plain. This power varies according to the sites as shown in Figure 14; 15; 16 and 17.

In the North-West zone the power of the plain varies between 30; 25 and 23 meters (Figure $14 ; 15)$. Towards the south and towards the west the power is also estimated at about twenty meters but it reaches 38 meters in some places (Figure 16;17). Table 2 gives the thickness of each of the main geological layers as well as the power of the plain per measurement site.

The following diagrams (Figure 18) allow us to better appreciate the distribution of materials at each level of the plain; but it should be noted that these diagrams have been plotted with the results of the profiles which gave better images of the basement 
respectively the LR00093, the LR106 and the LR102 for the North West, West and South zones; knowing that the other profiles in the same zones give more or less the same proportions.

The northwestern and western zones show dominance in clay alluvium compared to the southern zone where gravel and sandy arena take up a considerable proportion.

Saturated and unsaturated thicknesses in the plain

Knowing the piezometry on the different studied sites, we can obtain the saturated and unsaturated zones knowing that the piezometric level constitutes the veil between the two.

However, the piezometry as well as the thickness of the plain varies from one place to another; which will also bring to vary the desired thicknesses. Table 3 shows this variation for a sample of seven (7) piezometers chosen in the vicinity of our ERT profiles.

\section{Plain's conceptual model}

As shown in the conceptual model (Figure 19), the greatest thicknesses are in the southern part of the plain towards Diarabakoko and Tangrela probably due to a basement depression in this area.

\section{Nature of the plain's limits}

The nature of the slopes of the Karfiguela plain has been determined by the combination of geophysical investigations and field observations of rocky outcrops.

The interpretation of the electrical resistivity models that will follow will allow us to determine the nature of the materials at the embankment level, in order to directly deduce the geological nature of the boundaries. We will use rectangular models for interpretation because these types of models are extended on the sides and therefore provide much more information about the boundaries.

At both sites represented by the above models, the slope of the valley is located at the electrodes No. 64.

For the LR98 model, the limit is made of materials with resistivities greater than 1000 ohm.m. These materials are in accordance with the geology in place, subsurface limestone and deep crystalline rock (granodiorite).

The LR102 model also represents the limit of the plain by materials with a resistivity higher than 1000 ohm.m but the field observations show that these materials are of the consolidated lateritic grave. This limit formed thereof becomes in depth the basement.

Inverted models of the other profiles gave similar results. Thus, in the same logic, we have been able to determine on all sites the geological nature of the materials that constitute the limit of the plain. The results are shown in Table 3.

The results in Table 4 show that on the studied sites, the limits of the plain are generally zero flow limits except in the case of LR00096 where we have a limit with variable potential.

But from our studies, we cannot determine the extension of each of the limits encountered, this would be possible if we had done photointerpretation to ensure a certain correlation between formations. So the results we have at this level are only relatively punctual. 
Table.1 Total groundwater resources in the Comoé basin in million m3 (GOMBERT, 1998)

\begin{tabular}{|l|l|l|l|l|l|}
\hline Sub-basin & Sedimentary area & Basement zone & Alluvium & Alterites & Total \\
\hline Upper Comoé & 25635 & 12370 & 90 & 96945 & 47740 \\
\hline Leraba & 19985 & 5295 & 40 & 6910 & 32230 \\
\hline Koudoun & 0 & 1560 & 10 & 0 & 1570 \\
\hline Baoué & 0 & 2000 & 10 & 1480 & 3490 \\
\hline Iroungou & 0 & 1170 & 10 & 1870 & 3050 \\
\hline Total & 45620 & 22395 & 160 & 19905 & 88080 \\
\hline
\end{tabular}

Table.2 Thicknesses of the main geological layers and power of the plain per site

\begin{tabular}{|c|c|c|c|c|}
\hline zone & $\begin{array}{c}\text { profile } \\
\text { designation } \\
\text { (site)) }\end{array}$ & Nature of the main geological layers & $\begin{array}{l}\text { Thickness of the } \\
\text { layers (m) }\end{array}$ & $\begin{array}{c}\text { Plain's power } \\
\text { (site) }\end{array}$ \\
\hline \multirow{12}{*}{ North-west } & \multirow{4}{*}{ LR00093 } & Clay materials & 20 & \multirow[t]{4}{*}{30} \\
\hline & & Sand & 4 & \\
\hline & & Gravel & 6 & \\
\hline & & Cracked and weathered granodiorite & 21 & \\
\hline & \multirow{4}{*}{ LR00094 } & Clay materials & 23 & \multirow[t]{4}{*}{25} \\
\hline & & Sand & 2 & \\
\hline & & Gravel & - & \\
\hline & & Craked and weathered granodiorite & - & \\
\hline & \multirow{4}{*}{ LR00096 } & Clay materials & 22 & \multirow[t]{4}{*}{23} \\
\hline & & Sand & - & \\
\hline & & Gravel & 1 & \\
\hline & & Craked and weathered granodiorite & - & \\
\hline \multirow{8}{*}{ West } & \multirow{4}{*}{ LR106 } & Clay materials & 20 & \multirow[t]{4}{*}{38} \\
\hline & & Sand & 7 & \\
\hline & & Gravel & 11 & \\
\hline & & Cracked and weathered granodiorite & 20 & \\
\hline & \multirow{4}{*}{ LR107 } & Clay materials & 22 & \multirow[t]{4}{*}{23} \\
\hline & & Sand & - & \\
\hline & & Gravel & 1 & \\
\hline & & Cracked and weathered granodiorite & - & \\
\hline \multirow{8}{*}{ South } & \multirow{4}{*}{ LR00098 } & Clay materials & 20 & \multirow[t]{4}{*}{22} \\
\hline & & Sand & 2 & \\
\hline & & Gravel & - & \\
\hline & & Cracked and weathered granodiorite & - & \\
\hline & \multirow{4}{*}{ LR102 } & Clay materials & 12 & \multirow[t]{4}{*}{38} \\
\hline & & Sand & 15 & \\
\hline & & Gravel & 11 & \\
\hline & & Cracked and weathered granodiorite & 13 & \\
\hline
\end{tabular}


Table.3 Saturated and unsaturated thicknesses of the plain

\begin{tabular}{lllll}
\hline $\begin{array}{l}\text { Désignation } \\
\text { profils }\end{array}$ & $\begin{array}{l}\text { Piézomètres } \\
\text { immédiats des } \\
\text { sites }\end{array}$ & $\begin{array}{l}\text { Puissances } \\
\text { plaine/site(m) }\end{array}$ & $\begin{array}{l}\text { Epaisseurs Non- } \\
\text { saturées/site (m) }\end{array}$ & $\begin{array}{l}\text { Epaisseurs } \\
\text { saturées/site (m) }\end{array}$ \\
\hline LR00093 & PZRG13 & 30 & 2.08 & 27.92 \\
\hline LR00094 & PZRD6 & 25 & 1.63 & 23.37 \\
\hline LR00096 & PZRG6 & 23 & 1.6 & 21.4 \\
\hline LR00098 & PZRG2 & 22 & 3 & 19 \\
\hline LR102 & PZRD7 & 38 & 0.63 & 37.37 \\
\hline LR106 & PZRD15 & 38 & 1.08 & 36.92 \\
\hline LR107 & PZRG7 & 23 & 0.8 & 22.2 \\
\hline
\end{tabular}

Table.4 Geological nature of the limits of the plain

\begin{tabular}{|l|l|}
\hline Profil & Geological nature of the plain \\
\hline LR00093 & Deep lateritic consolidated in subsurface, deep granodiorite \\
\hline LR00094 & Poorly consolidated sandstone \\
\hline LR00096 & Deep lateritic consolidated in subsurface \\
\hline LR00098 & Limestone \\
\hline LR00102 & Consolidated sandstone \\
\hline LR00106 & Limestone \\
\hline
\end{tabular}

Fig.1 Map of the geographical location of the study area (SIG VREO, 2008, NESTOR 2017)

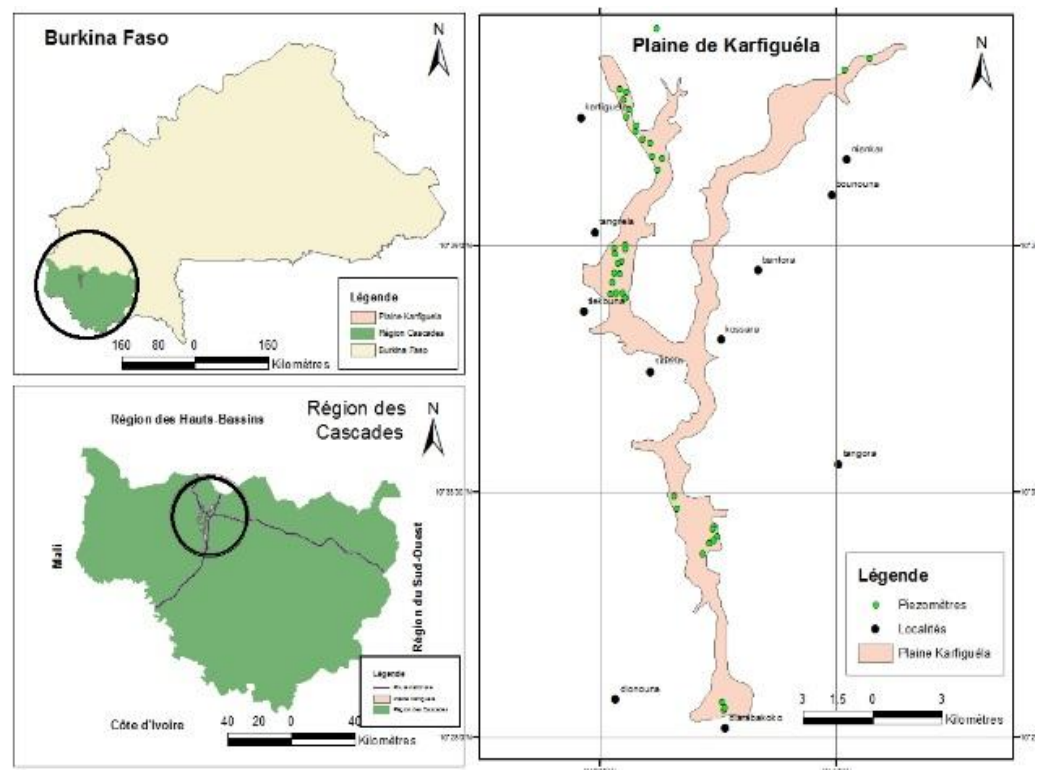


Fig.2 Geology of the study site (NESTOR 2017

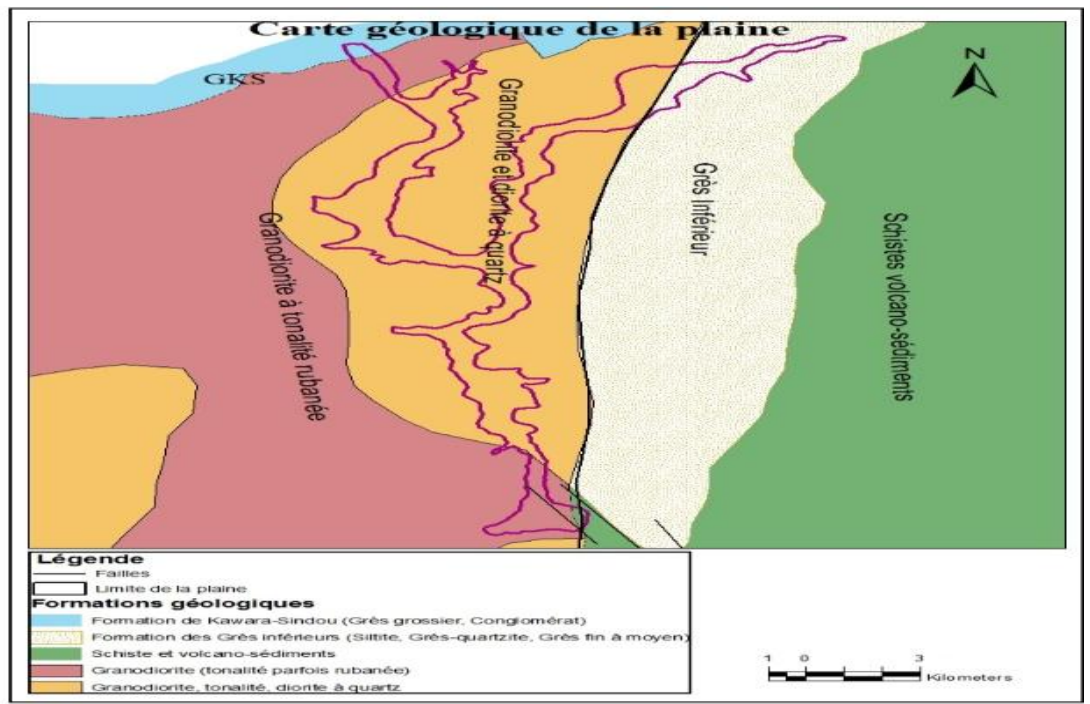

Figure.3 Kawara sandstone Sindou foliated (A), Kawara sandstone Sindou healthy (B)
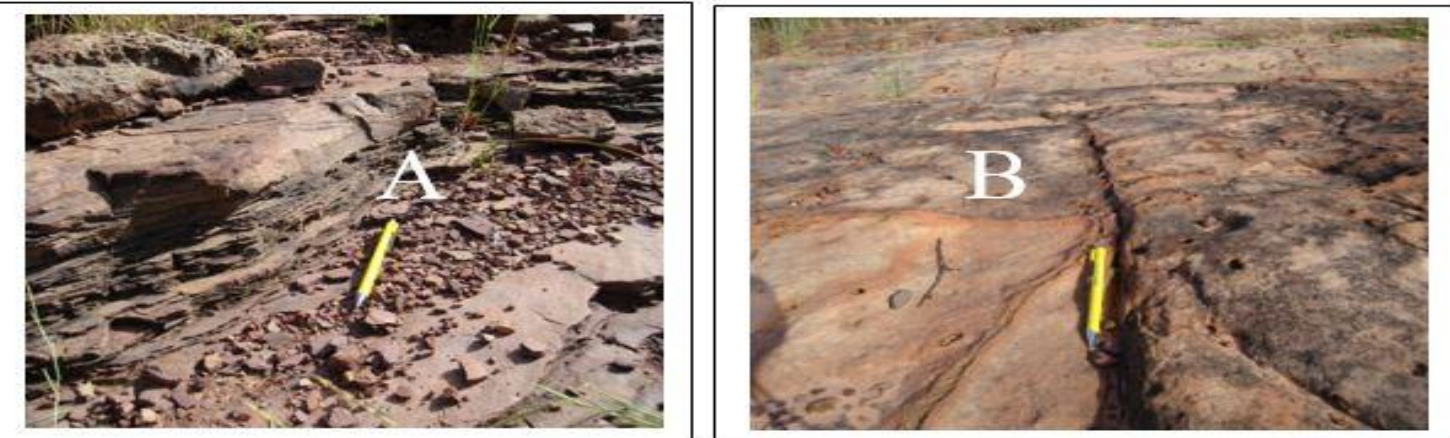

Figure.4 Distribution map of ERT profiles

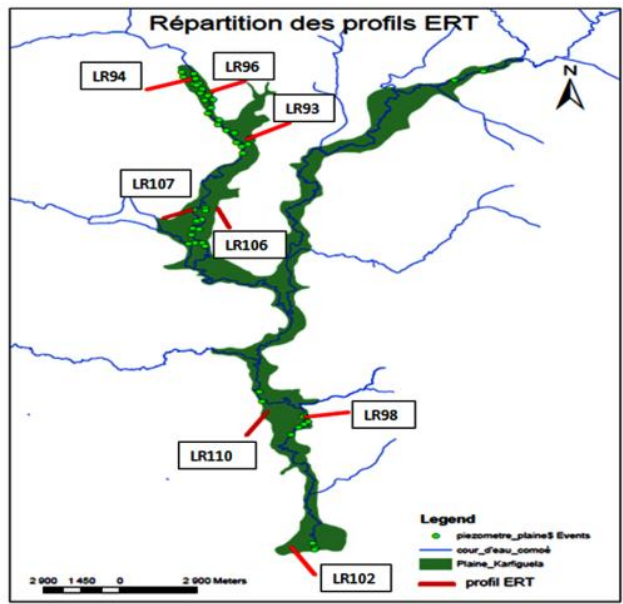


Figure.5 Measuring site $\mathrm{n}^{\circ} 7$ in Tengrela (A); measurement site $\mathrm{n}^{\circ} 2$ located at the level of the cascades (B), presence of high voltage pound (noise)
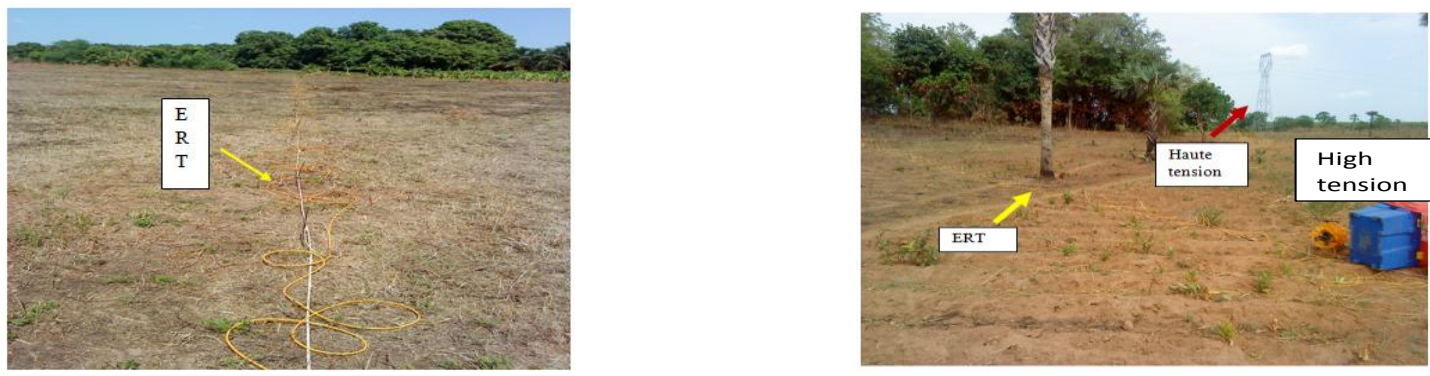

Fig.1 Wenner Configuration

\section{Wenner}

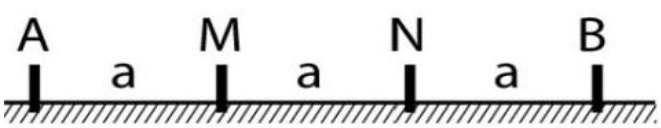

$$
\mathrm{K}=2 \pi \mathrm{a}
$$

Fig.7 Representation of the electrode arrangement for a Wenner device acquisition with different acquisition levels

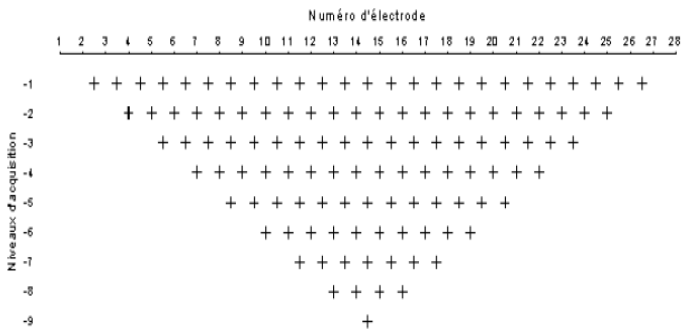

Fig.2 Inverted model of electrical resistivity of LR00093 profile

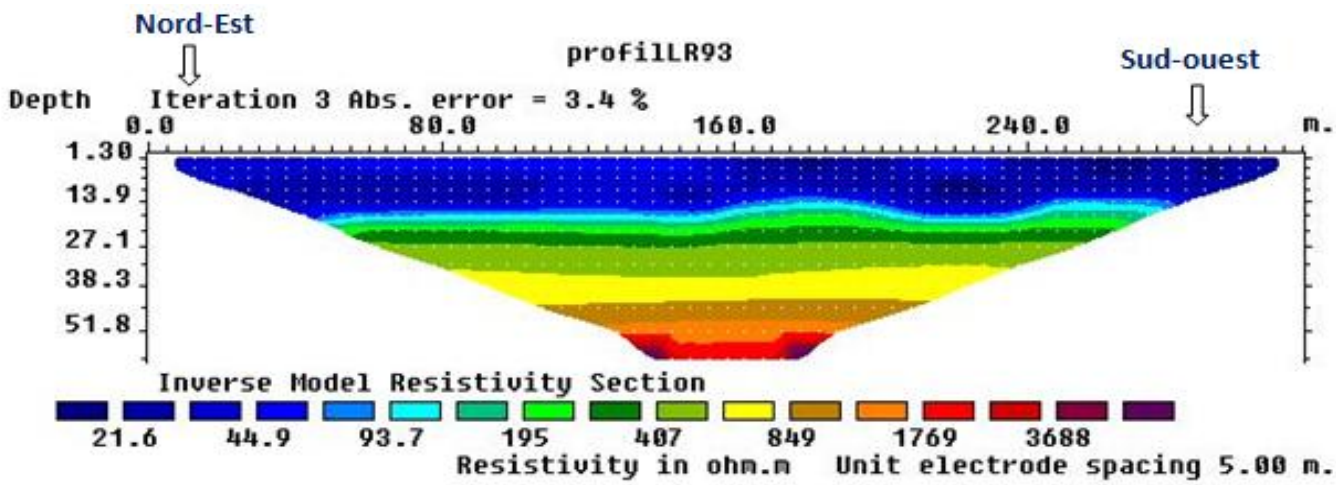


Fig.3 Lithological cutting of profile LR00093

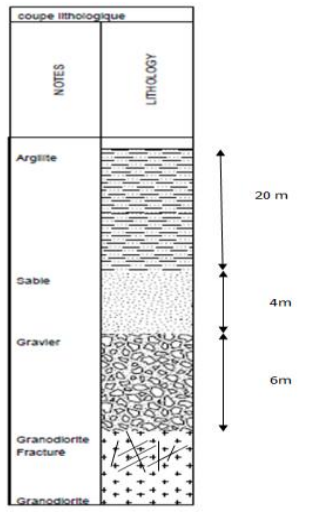

Fig.4 Stratigraphic section of PZRG21 and PZRG22 boreholes

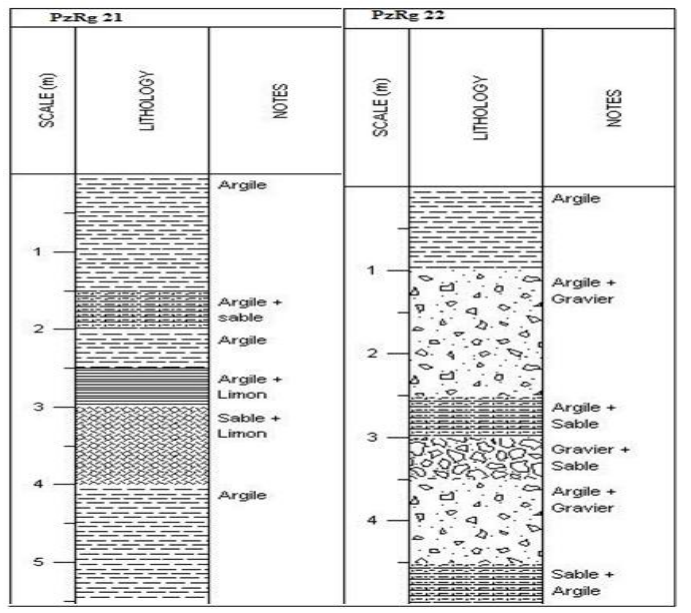

Fig.5 Electrical resistivity model of the LR106 and LR107 profiles
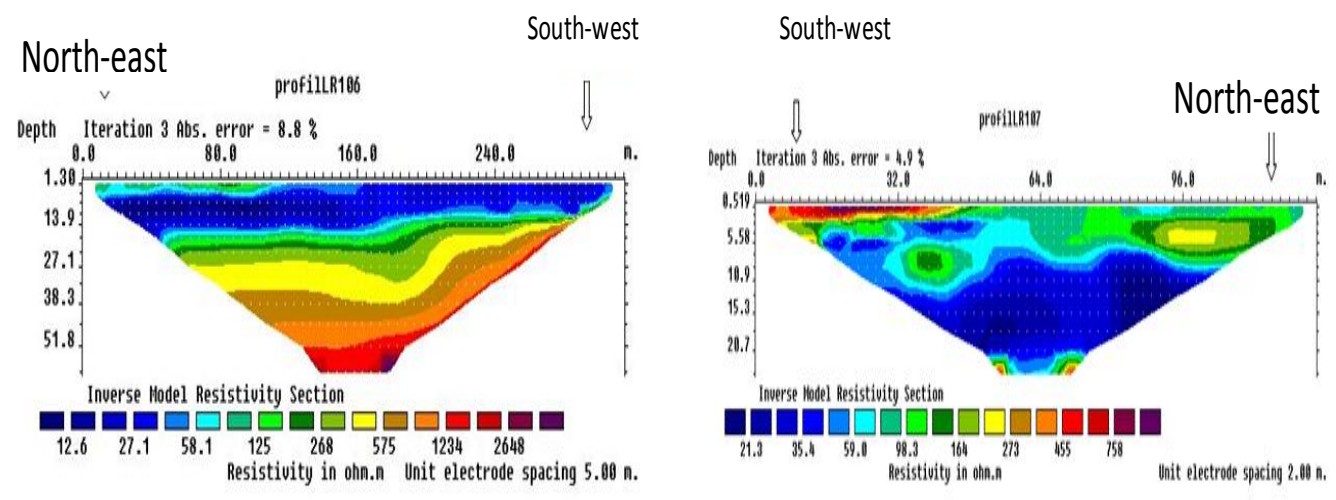
Fig.6 Lithological sections of the LR106 and LR107 models

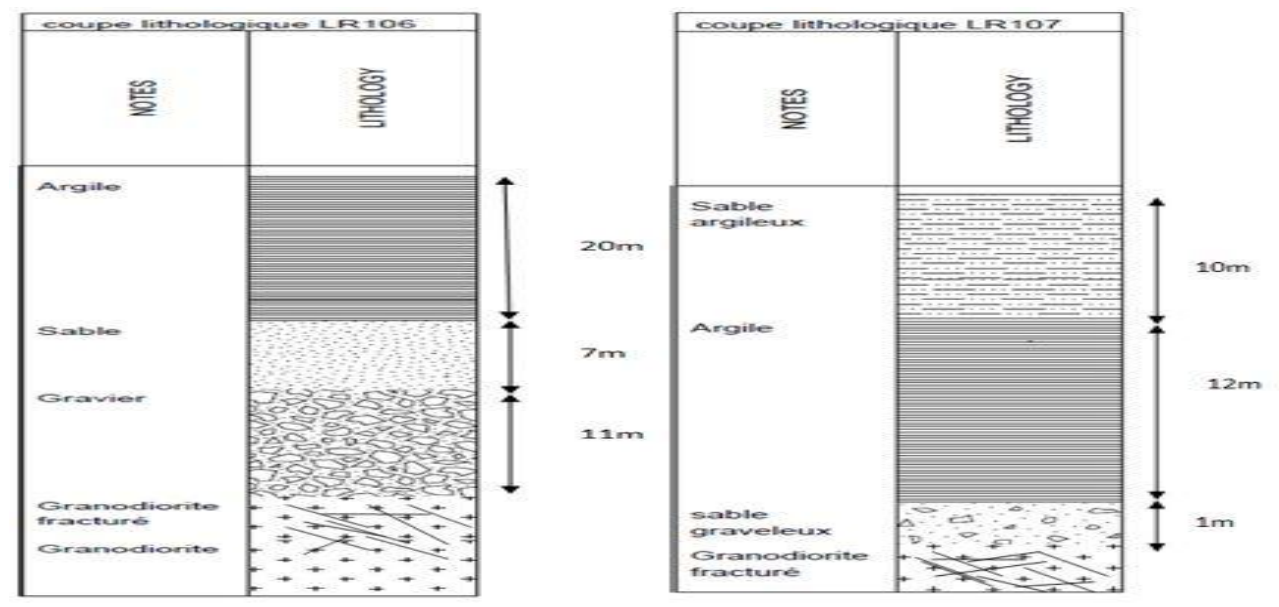

Fig.7 Stratigraphic cut of PZRDG and PZRDF boreholes

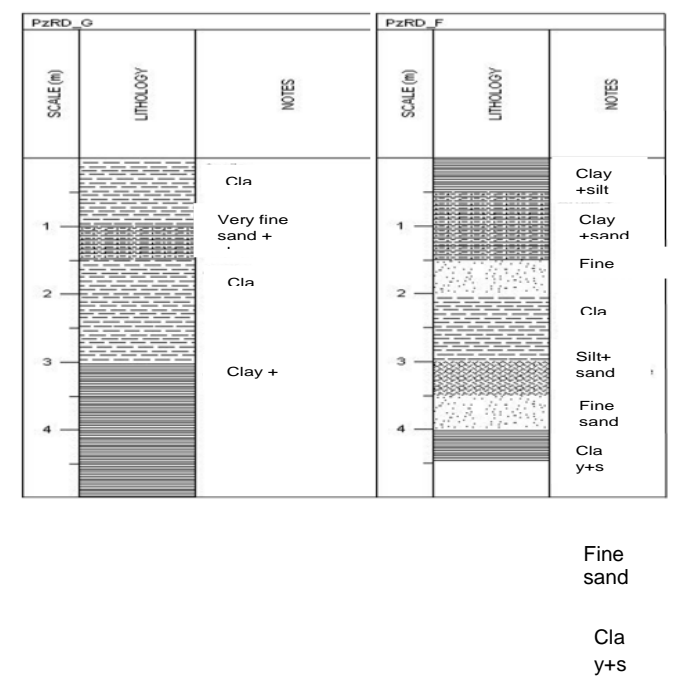

Fig.8 Lithological section of profile LR00093

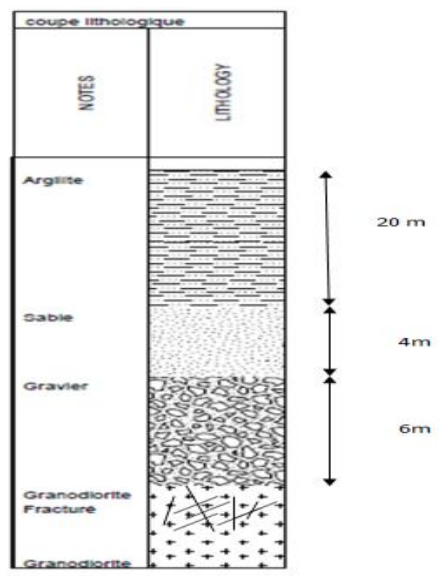


Fig.9 Lithological sections of models LR00094 and LR00096

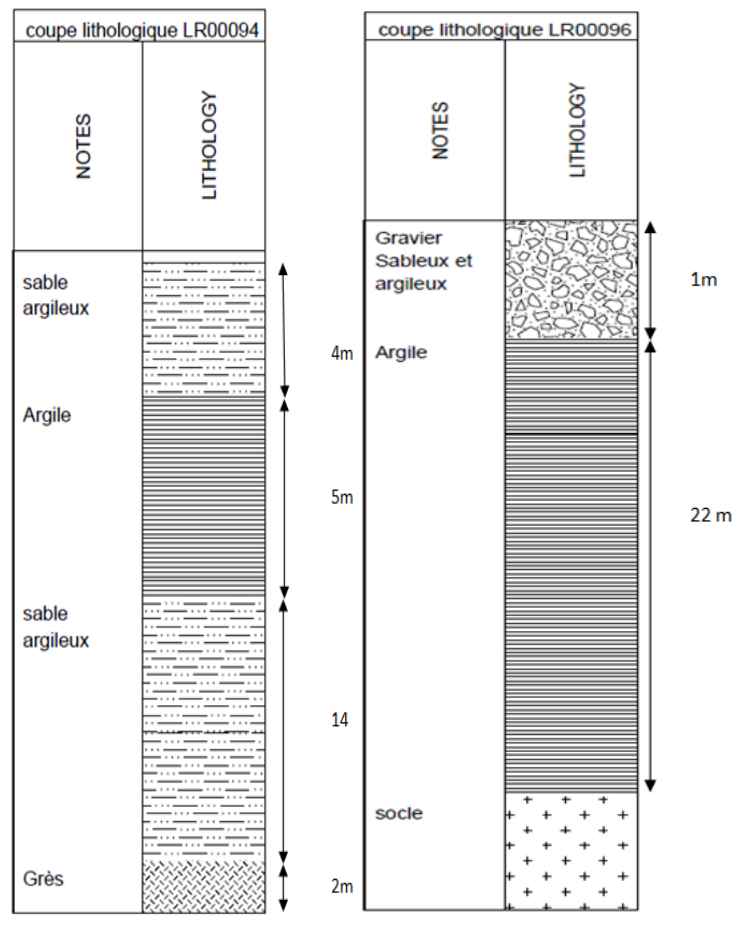

Fig.10 Lithological cut of models LR106 and 107

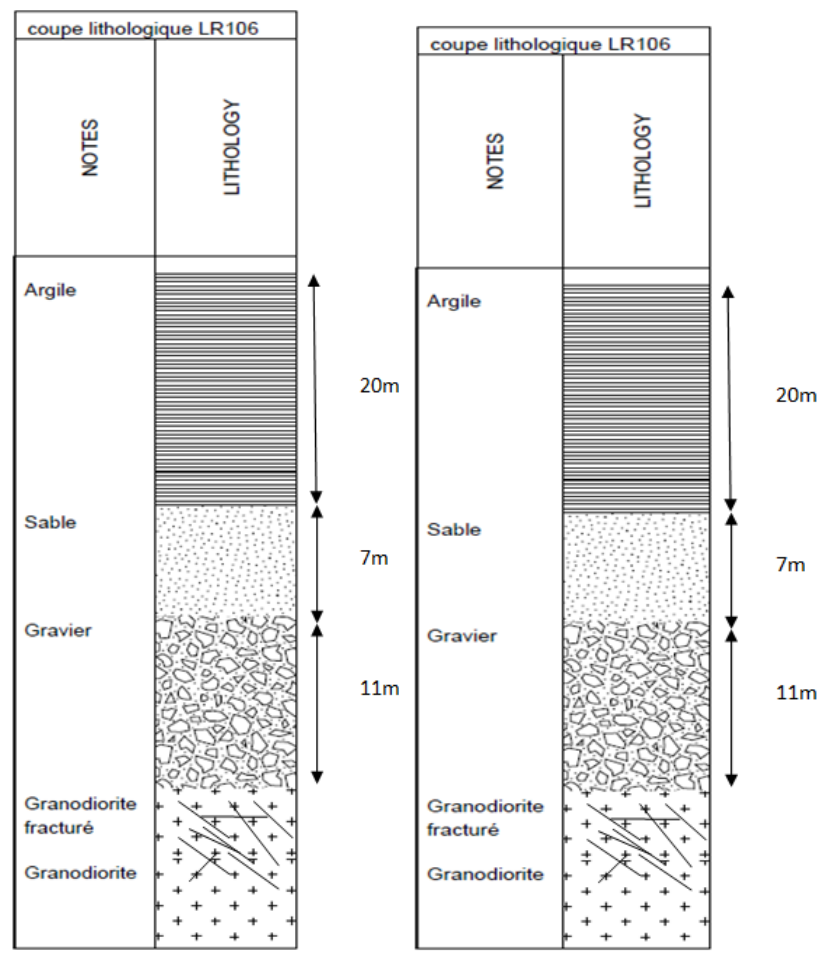


Fig.11 Lithological sections of models LR00098 and LR102

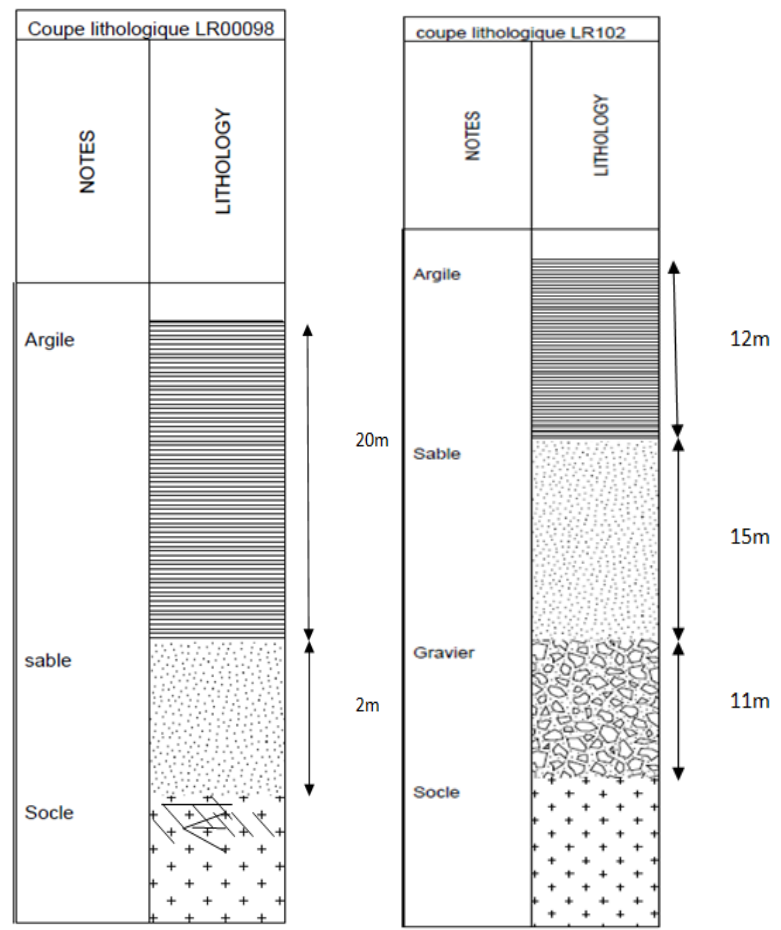

Fig.12 Vertical distribution of materials in the plain
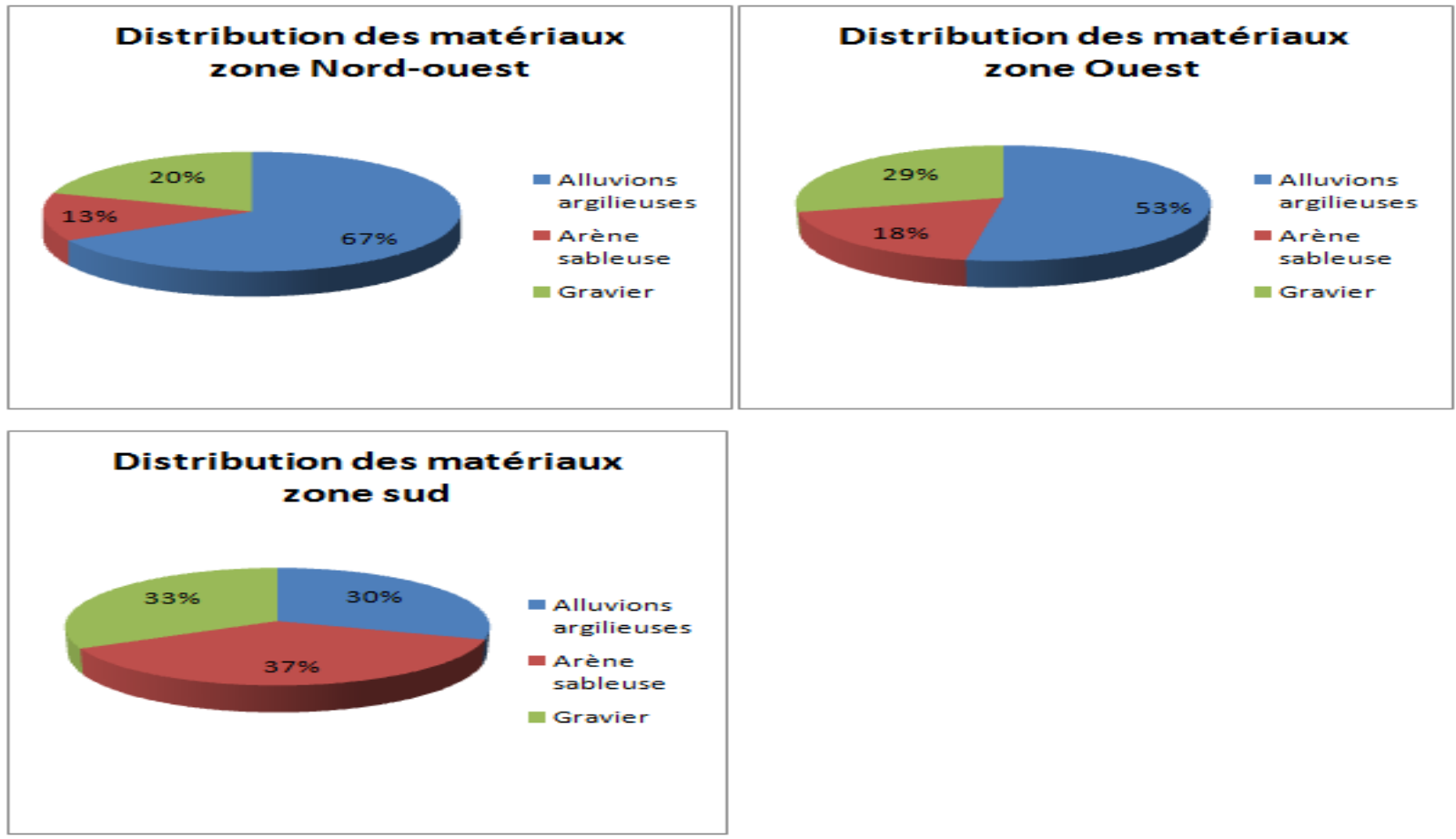
Fig.13 3D Conceptual model of the plain

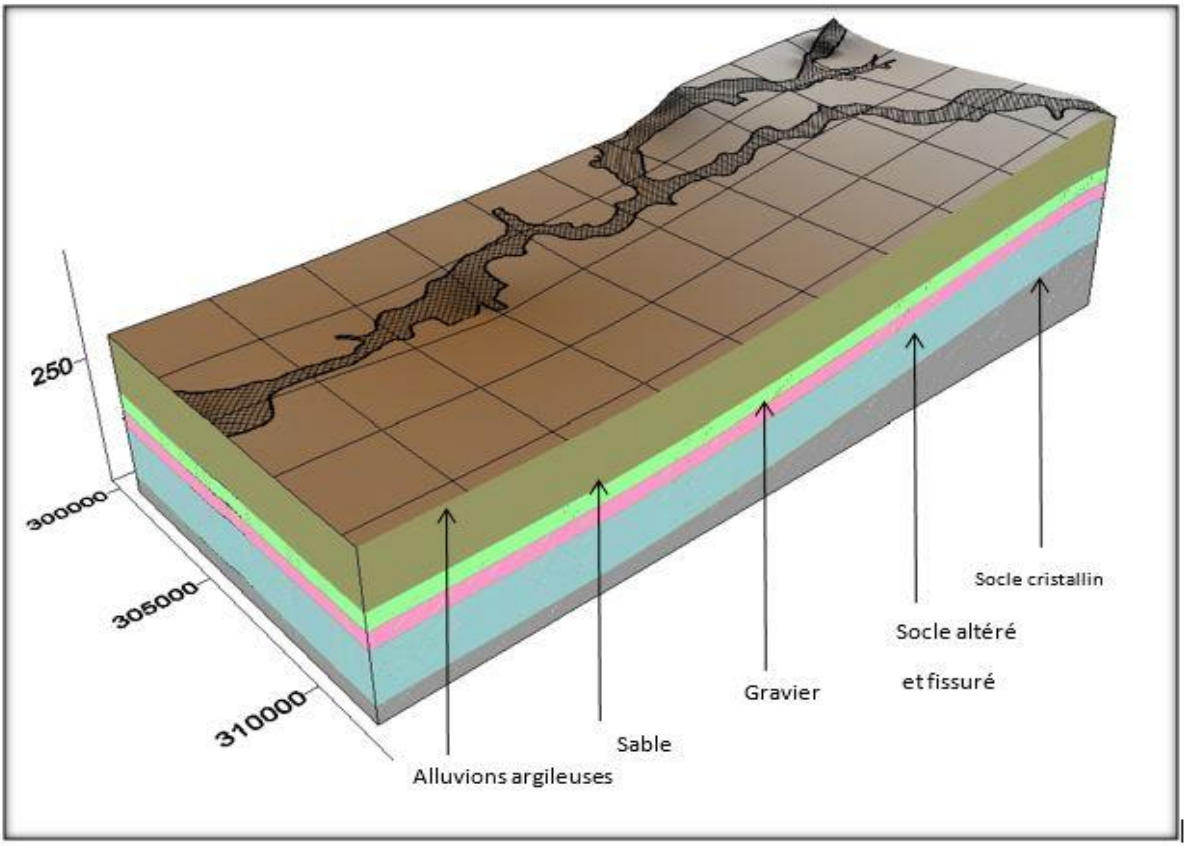

Fig.14 Extended models of LR102 profiles at the top and LR98 at the bottom

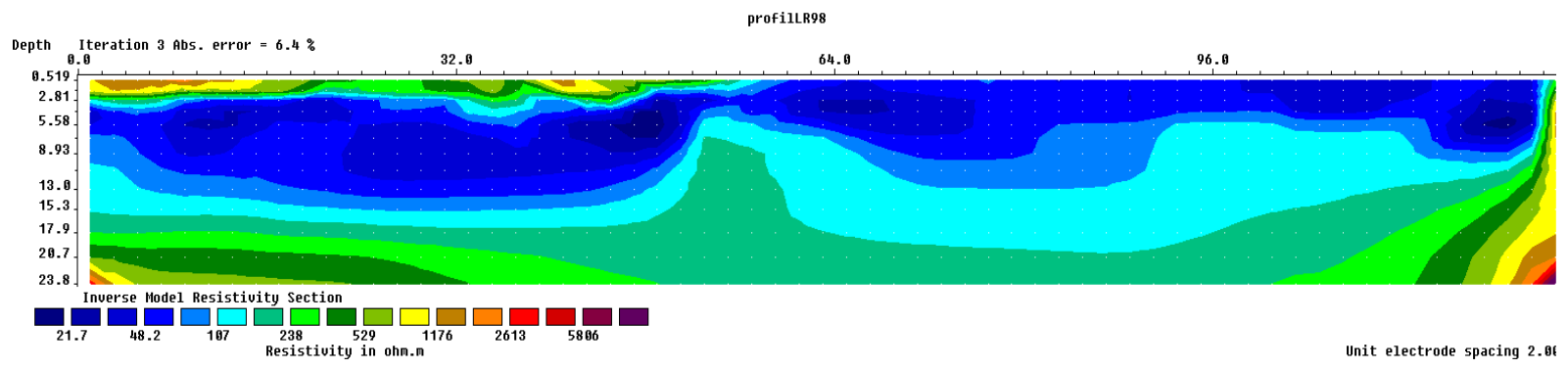

profillR102

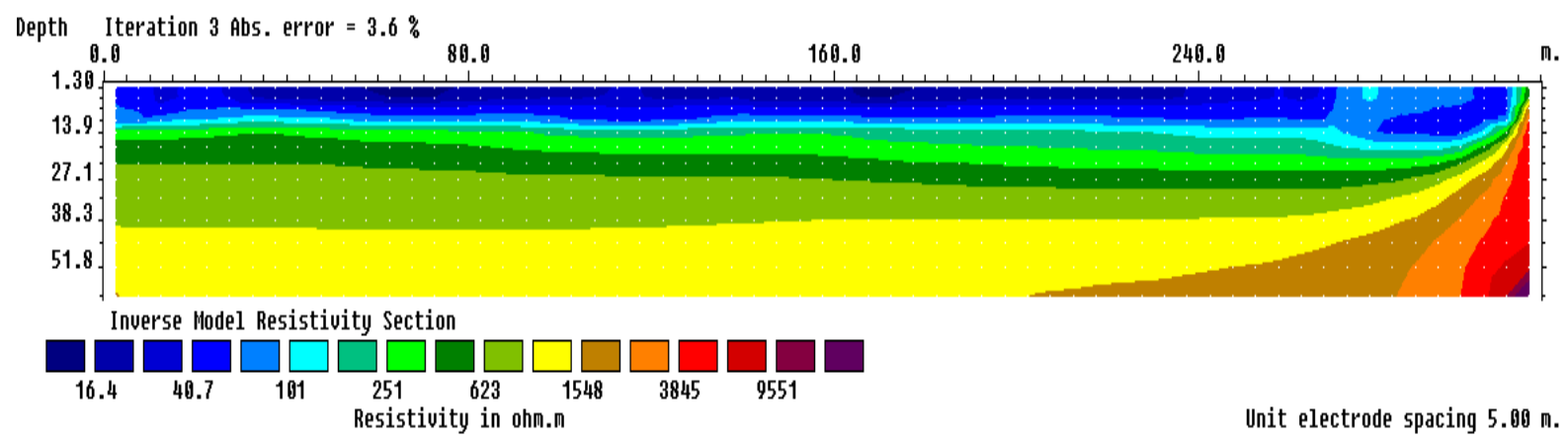


In conclusion the soils of the alluvial plain of Karfiguela are generally very suitable for agriculture. However, the considerable decrease of the flow of the river in the dry season that has spread to the large plain is problematic. To overcome this, a solution has been found.

Indeed, the solution adopted was to study the alluvial aquifer so that it could be a source of water complementary to the peasants, thus enabling them to carry out agro-pastoral activities in the wet season as well as in the dry season.

The aim of the study was to know not only the nature of the constituent materials of the alluvial aquifer but also to know its power knowing that these two parameters play an important role in quantifying the underground water resource.

The tomography of electrical resistivity associated with the wenner protocol was the geophysical technique that we used for this study. It is well suited for the characterization and vertical highlighting of horizontal layers. To support and confirm our geophysical results, we carried out forty nine (49) destructive probes (micro piezometers) auger, 6 meters deep, each with its stratigraphic log designed by tactile diagnosis from a one-step sampling. 0.5 meters. These samples were also subjected to a granulometric analysis in order to support the tactile diagnosis and to have an idea on the weight distribution of the grains of different diameters.

At the end of this analysis the overall picture that could be drawn was that particle size curves spread with grain diameter between 16 $\mathrm{mm}$ and less than $0.08 \mathrm{~mm}$. All the methods led to the same results, which testify to the reliability of these studies. Geophysical measurements allowed us to detect ranges of resistivities ranging from the weakest $(<100$ ohm.m) for the highly conductive materials, through the averages (100 to $1000 \mathrm{ohm} . \mathrm{m}$ ) to finish at the strongest (> $1000 \mathrm{ohm} . \mathrm{m}$ ).

These resistivity values show a heterogeneity of the materials at the level of the studied plain and can be classified in three main groups according to the geology: The very clayey alluvium constituting the majority of the plain with proportions up to $67 \%$ according to the sites; sand and gravel occupying relatively small proportions. The power of the plain varies considerably according to the sites, it reaches 38 meters in the west and south zones, with saturated thicknesses varying between 19 and 37 meters

Today, we know the tabulation, the nature and the granulometry of the different materials of the plain from the topographic surface to the bedrock. We know what any potential reservoirs, their powers, their saturated and unsaturated thicknesses and their localization depths. This could therefore be a solid database for future implementation of productive works. Among the objectives, it was also a question of knowing the geological nature of the limits of the plain. This was determined by geophysics and field observations. Overall on the studied sites we have impermeable limits because constituted of crystalline rocks and / or compact sedimentary rocks. But this information is only punctual, to define the extent of these limits, a photo-interpretation study is necessary because it will make some geological correlation.

\section{References}

1. Dezelter Alain, 1998 water resources variability in Africa during the 20th century. Wallingford: AISH; (252) 387-394

2. DGH. (2001), État des lieux des ressources en eau du Burkina Faso et 
de leur cadre de gestion, programme gire, version finale, 251P. Ministère de l'Environnement et de l'Eau, Secretatriat Général de l'Hydraulique, Direction Général de l'Hydraulique, Gestion Intégrée des Ressources en Eau

3. Nestor F. COMPAORE, Amagana E. DARA, Mahamadou KOITA, Hamma Fabien YONLI 2017 Assessment of the Exploitation and Sustainability of an Alluvial Plain in Southwestern Burkina Faso. Journal of Natural Sciences (2): 16-22.

4. HUGOT G. (2002), In search of lost Gondwana: at the origins of the world U.M.R. 6012 of C.N.R.S (espace)

5. Ouedraogo. C. (2006), geological synthesis of the western region of Burkina Faso, VREO program, PP 2035.toRESO, 1998
6. GOMBERT

7. MARESCOT L. Imagerie électrique pour géologue. 2008 version 2008a $73 \mathrm{pp}$

8. Haladou Laouali Caractérisation des matériaux et de la puissance de la plaine de Kafiguéla par investigations géophysiques; mémoire Master. Institut International de l'Ingénierie de l'eau et de l'Environnement

9. SYMBORO Aly et Compaoré Nestor Fiacre (2016), Gestion quantitative et qualitative des ressources en eau dans la plaine alluviale de Kafirguéla à l'aide d'un SIG: Etude de la recharge induite de la nappe et sa vulnérabilité. 7th RWSN Forum «Water Eveyone 29 nov. -2 déc. 2016 Abidjan RCI

\section{How to cite this article:}

Nestor Fiacre Compaore and Samuel Nakolendousse. 2019. Geophysical Characterization of an Alluvial Plain: Case of Karfiguela in Burkina Faso. Int.J.Curr.Microbiol.App.Sci. 8(01): 725741. doi: https://doi.org/10.20546/ijcmas.2019.801.080 